\title{
A REPRESENTAÇÃO DO ESTRANGEIRO E DO ESTRANHO EM “FRONTEIRA NATURAL”, DE NÉLIDA PINÕN
}

Suely Leite

\section{RESUMO:}

A literatura constitui-se em terreno fértil para a ficcionalização das experiências humanas, entre elas a interação do indivíduo com o Outro e consigo mesmo. Essa interação reflete semelhança e estranheza, facetas que compõem a totalidade múltipla do ser. O conto "Fronteira Natural" de Nélida Piñon, publicado em 1973, na coletânea intitulada Sala de Armas, é exemplar dessa arquitetura. O protagonista da narrativa parte de sua aldeia rumo ao inferno, em busca de uma completude nunca encontrada diante dos seus. Ao regressar, torna-se portador de um todo indivisível com a natureza, identidade que passa a ser almejada por todos da aldeia. O texto nos remete a tradição narrativa, pois estrutura-se em torno de três pilares: o jovem herói, o inferno e a viagem. A figura do jovem carrega o estereótipo de uma existência destinada a uma busca. O inferno é o espaço estrangeiro, desconhecido, o reino mais rico, atraente, que oferece ao jovem da aldeia a completude identitária tão desejada; nele estabelece-se a dicotomia entre norma e diferença, estrangeiro e estranho. A análise do texto percorrerá os estudos sobre o duplo exterior, tema recorrente na obra de Julia Kristeva.

\section{PALAVRAS-CHAVE:}

Conto maravilhoso; estrangeiro; estranho; Nélida Piñon.

A viagem não começa quando se percorrem distâncias, mas quando se atravessam as nossas fronteiras interiores. A viagem acontece quando acordamos fora do corpo, longe do último lugar onde podemos ter casa.

[...] A viagem termina quando encerramos as nossas fronteiras interiores. Regressamos a nós, não a um lugar.

(Mia Couto, O Outro Pé da Sereia)

A literatura constitui-se em terreno fértil para a ficcionalização das experiências humanas, entre elas, a interação do indivíduo com o Outro e consigo mesmo. Não é de hoje que o tema duplo tem sido fonte de inspiração para a pena de diversos escritores e objeto de deleite de inúmeros leitores. Nicole Fernandez Bravo, uma das grandes estudiosas do assunto, diz que o conceito de "duplo", tal qual o conhecemos no âmbito dos estudos literários, passou a ser difundido com mais destaque a partir do final do século XVIII. De acordo com a autora, 
uma das primeiras denominações do duplo é o de alter ego. [...] O termo consagrado pelo movimento do romantismo [alemão] é o de Doppelgänger, cunhado por Jean-Paul Richter em 1796 e que se traduz por "duplo", "segundo eu". Significa literalmente "aquele que caminha do lado", "companheiro de estrada". Endossamos a definição dada pelo próprio Richter: "assim designamos as pessoas que se vêem a si mesmas". O que daí se deduz é que se trata, em primeiro lugar, de uma experiência de subjetividade (2000, p. 261).

Ainda que sua eflorescência tenha ocorrido na Alemanha, durante a era romântica, é sabido que o duplo remonta a épocas bem mais remotas. Suas profundas raízes encontram-se presentes na consciência mitológica de povos antigos. Em O homem e a morte, de Edgar Morin, e, mais especificamente, em $O$ duplo, de Otto Rank, é possível observar o trabalho dos estudiosos no sentido de esquadrinhar a questão do duplo no imaginário desses povos, através de fontes do tipo: folclore, histórias de magia, antigos costumes religiosos e demais tradições.

Recorrendo a diversos folcloristas, Otto Rank constata que, nas línguas de variados povos, uma mesma palavra pode significar "sombra", "espírito", "alma", "imagem", "reflexo", "eco" e "duplo". De acordo com o estudioso, "variada série de relatórios, apresentados em folclore, põe fora de dúvida o fato de que o homem primitivo considera [ser, por exemplo,] a sombra seu misterioso duplo, como um ser espiritual, porém real" (1939, p. 93). Como faz notar Edgar Morin, não se trata de um elemento que se manifesta apenas depois da morte:

Esse duplo não é tanto a reprodução, a cópia conforme post mortem do indivíduo falecido: acompanha o vivo durante toda a sua existência, duplica-o, e este último sente-o, conhece-o, ouve-o e vê-o, por meio de uma experiência quotidiana e quotinocturna, nos seus sonhos, na sua sombra, no seu reflexo, no seu eco (1988, p. 126).

Todo esse material histórico cultural testemunha o eterno problema do homem que, marcado por um profundo sentimento de incompletude, busca na figura do Outro a possibilidade de se preencher. O conto "Fronteira Natural", de Nélida Piñon, publicado em 1973, na coletânea intitulada Sala de armas, é exemplar dessa arquitetura. Nos contos ali reunidos, observa-se a poderosa onipresença do universo mítico. A própria autora, em seu site oficial, define a obra como

um conjunto de relatos, uns mais irônicos, outros mais líricos, mas sempre com esta atmosfera de estranheza, porque o mundo é um grande reino de confusão. Temos que desconfiar de nossas estruturas emocionais, de nossas estruturas verbais, pô-las em quarentena e continuar buscando (2012).

O conto é marcadamente curto, possui aproximadamente dez páginas, e é narrado em terceira pessoa, afastando o leitor dos personagens, tirando-lhes a voz. O enredo proposto pela autora tem como foco uma viagem. O protagonista da narrativa parte de sua aldeia rumo ao inferno, em busca de uma completude 


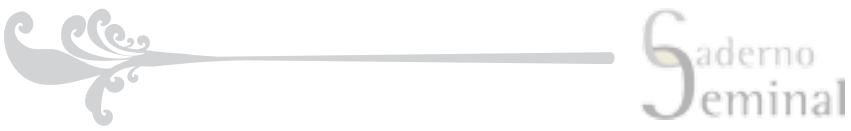

nunca encontrada diante dos seus. Ao regressar, torna-se portador de um todo indivisível com a natureza, identidade que passa a ser almejada por todos os habitantes da aldeia. O que antes era sinônimo de medo, por ser desconhecido, passa a ser assumido pelos aldeões como o caminho a ser percorrido para alcançar o além da fronteira. O silêncio do jovem aldeão ao retornar é o código indecifrável da magia advinda do inferno.

O texto nos remete à tradição narrativa, pois estrutura-se em torno de três pilares: o jovem herói, o inferno e a viagem. A figura do jovem carrega o estereótipo de uma existência destinada a uma busca. O inferno é o espaço estrangeiro, desconhecido, o reino mais rico, atraente, que oferece ao jovem da aldeia a completude identitária tão desejada. Nele, estabelece-se a dicotomia entre norma e diferença, estrangeiro e estranho. A viagem representa a busca da individuação, o legado que faz com que o jovem desperte a inveja dos outros habitantes da aldeia. Sua presença, após o regresso, é vista como a de alguém estranho à cultura que pertencera, estrangeiro no seu modo diferente de viver, e, por isso, atrai o coletivo, que vê, na figura do estrangeiro, o espelho da identidade que buscam ter.

O tema da viagem é bastante caro à literatura. Esteve presente nas grandes epopeias e continua sendo o arquétipo para muitas narrativas. A viagem é um deslocamento que pode alocar vários significados: pode ser deslocamento geográfico, temporal, como pode também significar um ritual de passagem. Enfim, nas suas diversas facetas, é possível encontrar viagens no tempo ou no espaço, mas, em todas elas, encontra-se a descoberta de si mesmo através do Outro. Pode-se dizer que a alteridade e a identidade surgem, de uma forma ou de outra, como elementos indissociáveis em toda a obra literária que tematize a viagem. Ela não é apenas uma translação no espaço, é também busca por mudança ou recuperação de uma experiência vivida.

Em "Fronteira Natural", o destino da viagem empreendida pelo protagonista é o inferno, adjetivado como reino estranho, do qual emanava um perfume harmonioso e para onde vários meninos haviam partido. Segundo consta, nem todos regressavam desse espaço, uma vez que "a maioria lá ficou para sempre" (Pinõn, 1988, p. 15)1. Os que de lá conseguiam retornar, eram tratados como estrangeiros, estranhos, exóticos, principalmente porque "emitiam sons de uma língua longínqua, terciária, sem dúvida, o esboço de uma linguagem buscando expressão" (p. 16). Ao ter empreendido uma viagem de ruptura com os vínculos da terra de origem, tais indivíduos tornam-se seres estigmatizados pela impossibilidade de estabelecer comunicação com os demais habitantes.

Além da língua estranha, eles também não reconheciam seus pares e apresentavam um modo diferente de olhar o mundo. Lê-se no conto que "haviam perdido a razão, concluíram os da aldeia". (p. 16). Assim dito, entre os habitantes daquele

1 As demais citações limitar-se-ão ao número de página desta edição. 
local, havia uma legião de estrangeiros que, embora fossem mostrados como troféus por suas famílias, viviam num mundo à parte, exilados em sua própria aldeia, "esquecidos da comunidade e nostálgicos de um mundo seguramente mais rico" (p. 16).

Essa condição de estrangeiro em terra natal nos permite relacionar tais representações às operações de (re)identificação e, principalmente, aos fatores de transculturação, visto que os egressos perdem o centro ou o equilíbrio entre as experiências vivenciadas. Embora a tentativa de interação com a cultura local fosse interrompida, a travessia da fronteira natural dava aos egressos um status. Tal como afirma o narrador, "nenhuma casa deixou de ostentar seu tesouro. Exibiam seus egressos nas varandas construídas especialmente para recebê-los" (p. 17).

A poética da alteridade privilegia a diferença cultural, a encenação da outridade. Ao encenar a travessia das fronteiras culturais, o narrador acena para uma subjetivização dessas fronteiras, aderindo, assim, à perspectiva psicanalítica que considera a alteridade como parte integrante do mesmo. Freud, no seu célebre artigo "O 'estranho'" (1919), defende a tese da imanência do estranho no familiar, o que leva Julia Kristeva, em Estrangeiros para nós mesmos, a afirmar, na sua releitura do ensaio freudiano, que o "estrangeiro nos habita". Em suas palavras, "o estrangeiro não é nem uma raça nem uma nação. [...] Inquietante, o estranho está em nós: somos nós próprios estrangeiros - somos divididos" (1994, p. 190).

A condição de estrangeiro, portanto de estranho - tal como proposto por Freud e revisitado por Kristeva -, provoca nos integrantes da aldeia sentimentos opostos. Se, por um lado, tais habitantes enalteciam os viajantes, exibindo-os como troféus, por outro, eles "temiam aquela raça consagrada à divindade" (p. 17-18). Por representarem o diferente e por terem conseguido dominar um conhecimento não aprendido no seu local de origem, eram admirados. Segundo o narrador, tais seres castravam os animais com ciência, alteravam o sistema de certos rios com propriedade. Todavia, quando essas demonstrações de poder cessavam, eram recolhidos, visto que sua inquietante estranheza incomodava. Assim dito, pode-se afirmar que pseudoaceitação dos egressos reforça o caráter de construção da identidade, pois envolve rejeição e aceitação. Em outras palavras, poder-se-ia dizer que a rejeição fascinada despertada na comunidade local pela figura do estrangeiro decorreria, pois, do fato desse elemento estranho cristalizar, por meio de suas competências extraordinárias, os anseios internos da coletividade.

O tempo marcado na construção da narrativa nos remete à Idade Média, tempo em que a sociedade organizava-se em torno da terra e o mundo era essencialmente agrário. Assim sendo, as pessoas fixavam-se à terra para seu cultivo e pouco transitavam. Os deslocamentos existentes eram raros e limitados e, quando ocorriam, 
destinavam-se à participação nas guerras, à realização de trocas comerciais e às peregrinações. Transitar e viajar, naquela época, constituía uma forma de protesto, contra a servidão à gleba. E é essa a tônica do conto: "Ainda que todos compreendessem aquela urgência, lamentavam em conjunto a insolvência mental de um homem de vinte anos" (p. 18). A aldeia representa o espaço da tradição que será quebrado pelo jovem rumo ao inferno. Estabelece-se a dicotomia entre o velho e o novo. Nesse embate de gerações, a incomunicabilidade da comunicação representa a incomunicabilidade entre as gerações. A diversidade semântica que recobre a problemática da viagem na literatura é inegável, mas, talvez, o mais significativo sentido que a viagem no tempo moderno adquire é o de romper com o espaço e com o tempo convencionais.

É desse espaço convencional que o protagonista do conto manifesta, aos vinte anos, o desejo de partir. Ele, "o mais amado da aldeia" (p. 17), empreenderá uma trajetória, associada à ideia da viagem, por onde trilhará caminhos em busca de sua própria identidade. Várias são as formas de apropriações do arquétipo da viagem pela arte literária. Mas o que é básico e permanece e, por isso, denominamos de mito, é o fato de que a viagem instaura para o viajante uma espécie de pausa em sua vida, provocando a separação do mundo conhecido desse viajante e colocando-o frente ao desconhecido, ao novo, à diversidade. Desse modo, o contato com a cultura do Outro obriga o viajante a tornar-se Outro sem deixar, no entanto, de si mesmo, oportunizando, assim, a descoberta da própria identidade. Conforme o narrador, tal jovem, "mais que desvendar terras, buscava a consciência no casulo, os meandros iniciais" (p. 17). As respostas aos seus muitos questionamentos não poderiam ser obtidas no espaço da pequena aldeia, era, pois, necessário descerrar as cortinas de um mistério de transfiguração.

A partida do jovem é cercada por um ritual: vestes partidas e choro da mãe, desfile pela aldeia, esperança de que na volta dominasse "a riqueza linguística do inferno" e, ainda assim, "seu verbo haveria de se fazer campesino para a aldeia" (p. 18).

O escritor e professor norte-americano Joseph Campbell, em seu livro O herói de mil faces, constata que o personagem do herói tem características diferentes e correspondentes a cada cultura, mas a sua peregrinação, a sua trajetória, a sua jornada na trama é, basicamente, a mesma e se estruturaria em etapas bem definidas, embora não necessariamente rígidas: a partida, a iniciação e o retorno. Normalmente a jornada do herói se constitui de uma aventura que pode ser tanto real como imaginária, obedecendo ao mesmo roteiro: o herói vive num mundo estável e recebe um chamado para partir e trilhar outro mundo, hostil e estranho. Desencadeia-se, então, uma série de ações na narrativa e, nessa jornada ao extraordinário, o herói terá de enfrentar provas e desafios num embate de vida e morte, morrer e ressuscitar, retornando ao mundo transformado, trazendo algo novo, como se fosse um prêmio. O herói, por desejar algo, se aventura e passa por sucessivas rupturas e deslocamentos. No que se refere 


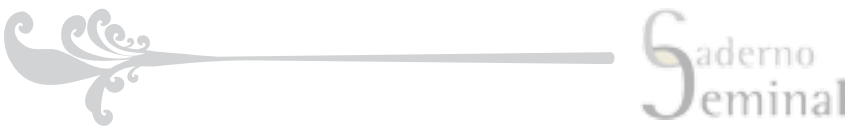

ao conto, os habitantes da aldeia viviam essa expectativa, "um sacrifício a pretexto da claridade" (p. 18), e "acompanhavam aquele corpo sofrendo talvez o dilaceramento da carne, o rosto inocente prestes a decifrar verdades cruéis" (p. 19). Em seu estudo, Campbell afirma que o retorno é a etapa em que,

terminada a busca do herói, por meio da penetração da fonte, ou por intermédio da graça de alguma personificação masculina ou feminina, humana ou animal, o aventureiro deve ainda retornar com o seu troféu transmutador da vida. O círculo completo, a norma do monomito, requer que o herói inicie agora o trabalho de trazer os símbolos da sabedoria, o Velocino de Ouro, ou a princesa adormecida, de volta ao reino humano, onde a bênção alcançada pode servir à renovação da comunidade, da nação, do planeta ou dos dez mil mundos.

Mas essa responsabilidade tem sido objeto de frequente recusa. (2007, p. 195).

Entre as ideias mais próximas do modelo dos ritos de passagem, nas viagens literárias, as mais relevantes são a aspiração ao aperfeiçoamento do conhecimento, através do pensamento e da experiência, e o caminho para uma nova ordem social e espiritual. No caso da aldeia, havia a esperança de que o mais amado trouxesse "um raciocínio que só em milênios a aldeia haveria de conquistar" (p. 19).

Com o passar do tempo e a ausência do jovem, a aldeia põe-se de luto e a expectativa da volta dá lugar ao medo. A ausência prolongada do jovem poderia sinalizar a sua morte, a perda do elo entre a aldeia e o inferno, o que significava uma ameaça à integridade daquele povo, pois o medo os transformou em seres passivos que temiam sofrer ainda mais as consequências que tal ato poderia desencadear: "Recordavam então os belos dias, quando o inferno vivia longe e não se partia em sua descoberta" (p. 20).

A volta do protagonista se dá num dia de sol, dia no qual ele se mostra "disposto a um amor de sufocação diferente" (p. 20). Volta, agora, um homem completo, não mais o jovem inquieto de antes, o que reitera o mito da viagem como uma caminhada para o autoconhecimento. Sérgio Paulo Rouanet, em seu texto "Viajar é preciso", afirma que "só os viajantes são inteiramente humanos" e que "os viajantes exercem, em sua plenitude, a prerrogativa máxima da espécie; a de cortar, consciente e voluntariamente, por algum tempo ou para sempre, os vínculos com o país de origem" (1993, p. 7). A liberdade adquirida durante o tempo em que passou por aquele reino estranho, é simbolizada pelo seu caminhar sem esbarrar nas coisas do mundo, a facilidade intemporal dos pássaros, o jeito livre de pisar, o conhecimento e o domínio da natureza. A viagem conferiu-lhe status de adulto. Vale ressaltar que o herói inaugurou uma nova fase para aquela aldeia, livre do medo e das crendices que faziam com que eles fossem escravizados e subjugados pelo medo de atravessar a fronteira que os separava de um novo mundo. O momento da narrativa no qual acontece a volta de um homem adulto simboliza o fim da viagem de autoconhecimento que o herói empreendeu. A inocência e a inquietude do jovem foram substituídas pela maturidade do adulto. 


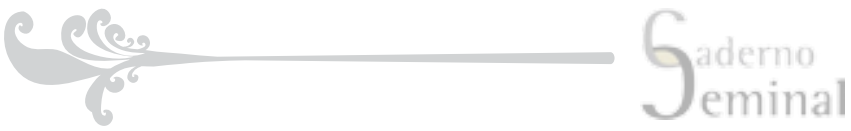

Agora, como homem, "senhor do arado" (p. 22), ele assume o papel de líder daquela aldeia. Sua passagem pelo inferno trouxe-lhe autonomia diante de seus pares: "Alcançara ele o desembaraço de quem conviveu em excesso com o milagre e, menos que sua virulência, nada mais devia aceitar" (p. 22). Segundo Otávio lanni, "no curso da viagem há sempre alguma transfiguração, de tal modo que aquele que parte não é nunca o mesmo que regressa" (2000, p. 31).

Ao se tornar mais um egresso da fronteira natural, o protagonista rompe com o que aldeia já estava acostumada: a linguagem estranha, a falta de comunicação dos poucos que haviam conseguido retornar da fronteira. A interação do homem com a terra, o domínio extraordinário que tem sobre a natureza, enfim, todas as novas características que o emblemam como imortal, o escolhido dos reinos soberanos, traz consigo o mistério maior: o silêncio: "E ainda que exigissem do homem qualquer fala, diferente dos outros egressos, ele vivia no silêncio. Desprezava signos, som, e a linguagem alheia" (p. 23).

O silêncio constitui-se no substrato ontológico do homem, essa tela de fundo, jamais atingível a não ser pela alusão, instaurando a alteridade dentro dele mesmo. É o silêncio primordial, aquele que determina as condições de possibilidade da linguagem. Esse silêncio, inominável, indizível, por ser passível de contato e de experiência, torna o sujeito seu protagonista. Comentando sobre o silêncio, tema de seu livro As formas do silêncio, Eni Orlandi, estudiosa da Análise do Discurso, faz a seguinte afirmação:

Trata-se do silêncio fundador, ou fundante, princípio de toda significação. [...] É a própria condição de produção de sentido. [...] Não é o vazio, ou o sem sentido; ao contrário, ele é o indicio de uma instância significativa [...] silêncio como sentido, como história (silêncio humano), como matéria significante. O silêncio de que falamos é o que se instala no limiar do sentido. [...] ele é o que há entre as palavras, entre as notas de música, entre as linhas, entre os astros, entre os seres [...]. (2007, p.68)

O silenciamento do protagonista provoca uma situação inusitada: o movimento do texto leva da fala ao silêncio, de maneira que o discurso passa a ser construído pela ausência, como se a palavra passasse por um esvaziamento. O silêncio é, no contexto do retorno da viagem à fronteira, um lugar seguro, aquilo que conserva o homem de forma mais completa e plena.

Quando se fala em viagem como tema de busca de autoconhecimento, o leitor, de imediato, recorda a descida aos Infernos de Ulisses e Eneias, as peregrinações dos cavaleiros medievais, o enfrentar de monstros por parte de Ulisses, Eneias, Beowulf, a passagem de grutas e portões, pelos heróis épicos e pelos cavaleiros dos romances medievais, conotadas com a viagem labiríntica de descida e subida, de acesso a uma libertação, a segredos recônditos, a um conhecimento tido por superior. Essa conotação também se faz presente no conto nelidiano, pois, agora, dotado de capacidades sobre-humanas que o tornam especial e, sobretudo, 


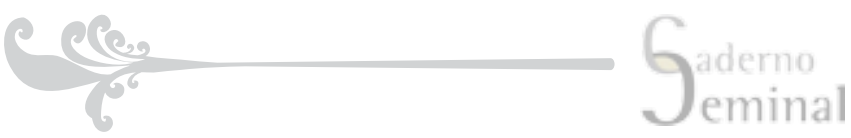

por sua agudeza de espírito, o protagonista passa a destoar inteiramente dos demais que, até então, apenas lamentavam a inexorabilidade de seus destinos, sem buscar os recursos para mudar tal situação.

Os habitantes da aldeia diferenciam o protagonista dos outros egressos. A identidade, o conhecimento adquirido no inferno passa a ser o objeto de desejo daquelas pessoas "e ainda que reconhecessem aquele homem por certo distante da terra, não queriam senão segui-lo" (p. 23). Então, coletivamente, elas se preparam para abandonar a aldeia rumo à fronteira natural: "Puseram-se em marcha. A aldeia toda" (p. 24) e encontraram a porta daquele reino fechada com uma pequena inscrição. O reino havia sido transferido para um local ignorado.

Assim termina o texto de Nélida Pinõn: revelando pouco, silenciando todo o resto, tudo que pode ser. Suas frases curtas calam sentidos inalcançáveis, despertam uma sensação profunda de incompletude. O silêncio que transpassa o texto é inquieto revelando-se potencialmente polifônico.

\title{
THE REPRESENTATION OF THE FOREIGN AND THE UNCANNY IN “FRONTEIRA NATURAL”, BY NÉLIDA PIÑON
}

\begin{abstract}
:
The literature is on fertile land for the fictionalization of human experiences, including the individual's interaction with the Other and oneself. This interaction reflects similarity and strangeness, facets that make up the totality of being multiple. The short story "Fronteira Natural " of Nelida Piñon, published in 1973 in the collection entitled Sala de Armas, is an example of this architecture. The protagonist of the narrative leaves from his village to hell in search of a completeness never found before her. Upon returning, becomes the bearer of an indivisible whole with nature, identity becomes a goal for all of the village. The text refers to the traditional narrative and it is structured around three pillars: the young hero, hell and the journey. The figure of the young man carries the stereotype of a life devoted to a search. Hell is the space alien, unknown, the richest kingdom, attractive, offering the youth of the village completeness identity so desired, it sets up the dichotomy between standard and difference, foreign and strange. The analysis of the text will cover studies on the double exterior, a recurring theme in the work of Julia Kristeva.
\end{abstract}

\section{KEY-WORDS:}

Marvellous short story; foreign; strange; Nelida Piñon 


\section{REFERÊNCIAS}

CAMPBELL, Joseph. O herói de mil faces. São Paulo: Cultrix, 2007.

FREUD, Sigmund. O 'estranho'. In: . História de uma neurose infantil e outros trabalhos (1917-1919). Vol. XVII. Trad. Eudoro Augusto Macieira de Souza. Rio de Janeiro: Imago, 2006. p. 235-273.

IANNI, Otávio. Enigmas da modernidade-mundo. Rio de Janeiro: Civilização Brasileira, 2000

KRISTEVA, Julia. Estrangeiros para nós mesmos. Trad. Maria Carlota Carvalho Gomes. Rio de Janeiro: Rocco, 1994.

MORIN, Edgar. O homem e a morte. Trad. João Guerreiro Boto e Adelino dos Santos Rodrigues. Mira-Sintra: Publicações Europa-América, 1988.

ORLANDI, Eni Puccinelli. As Formas do Silêncio: no movimento dos sentidos. Unicamp, 1992.

PIÑON, Nélida. Sala de armas. Rio de Janeiro: Francisco Alves, 1988.

Site oficial: biografia. Disponível em: http://www.nelidapinon.com.br/ autora/aut_biografia.php. Acesso em: 20 jun. 2012.

RANK, Otto. O duplo. Trad. Mary B. Lee. 2. ed. Rio de Janeiro: Coeditora Brasílica, 1939.

ROUANET, Sérgio Paulo. Mal-estar na Modernidade. São Paulo: Companhia das Letras, 1993. 